\title{
Study on Tourist Cooperation Based on Game Theory
}

\author{
Sun Guoxue
}

College of Economics and Management, ChiFeng University, ChiFeng, Inner Mongolia, China (sgx500@163.com)

\begin{abstract}
Regional cooperation in tourism is tourism development to a certain stage of the product, Is the inevitable trend of development of tourism economy, For enhancing the competitiveness of the tourism industry and sustainable development are of great significance. From the perspective of game theory, Explore the necessity and importance of regional tourism cooperation, Depth study the main body of regional tourism cooperation, and content areas of cooperation and the establishment of cooperation mechanisms and other issues, To grasp the direction of development for tourism cooperation, Combing the idea of cooperation in tourism, Tourism is particularly important to speed up the process of cooperation.
\end{abstract}

Key words---Game theory, Tourism cooperation, Areas of cooperation, Cooperation mechanisms

\section{基于博弯理论的旅游合作问题研究}

\author{
孙国学 \\ 赤峰学院经济与管理学院, 赤峰, 内蒙古, 中国
}

摘 要 区域旅游合作是旅游业发展到一定阶段的产物, 是旅游经济发展的必然趋势, 对于提升旅游业竞争力的和实现可持续发 展都具有重要意义。从博弯理论的视角, 探讨区域旅游合作的客观必然性和重要性, 深入研究区域旅游合作的主体、合作的领域和内 容, 以及合作的保障机制等问题, 对于把握旅游合作发展方向, 理清旅游合作思路, 加快旅游合作进程尤为重要。

关键词＼cjkstart博弯理论，旅游合作，合作领域，合作机制

\section{1. 引言}

区域旅游合作是不同地区间的社会经济主体，为了完 成某些重大的旅游发展计划或为了谋取某种共同的经济效 益、社会效益及生态效益, 依据一定的协议或章程, 自愿 进行的自利性与互利性相统一的旅游经济活动形式。区域 旅游合作是旅游业发展到一定阶段的产物, 是区域旅游经 济发展的必然趋势, 对于区域内旅游业竞争力的提升和实 现可持续发展都具有重要意义。

\section{2. 博弯视角下的区域旅游竞争与合作}

博亦论一般认为, 博亦主要可以分为“正和博亦”和“零 和博亦”。正和博弯亦称为合作博亦, 是指博亦双方的利益 都有所增加, 或者至少是一方的利益增加, 而另一方的利 益不受损害, 因而整个社会的利益有所增加。零和博亦又 称零和游戏, 与非零和博亦相对, 属非合作博亦, 指参与 博亦的各方在严格的竞争下, 一方的收益必然意味着另一 方的损失, 博亦各方的收益和损失相加总和永远为 “零”,
双方不存在合作的可能。

从国际和国内旅游发展的实际考察, 旅游业具有鲜明 的区域性。这种区域性既与资源、要素等旅游供给的区域 性分布有关, 也同旅游需求的区域性形成相关联, 空间上 表现为向心的中心地理结构。由于旅游资源分别归属于不 同的行政区，导致区域旅游合作存在着地域分割、行为主 体不同、认识差异等障碍, 使双方在旅游资源开发与管理 中容易产生利益冲突。因此, 在市场经济条件下, 区域旅 游竞争是普遍的。

但旅游业作为关联程度、开放程度极高的新型产业, 由于旅游资源禀赋的空间互补性、旅游活动的空间连续性 和区域文化内涵的相对一致性, 旅游业深入发展使得不同 旅游地之间并非仅仅是 “零和博亦” 的竞争关系, 而且可以 是互利双赢的合作关系, “正和博亦”的区域旅游合作同样 是必然的。因此, 越来越多的地区从各自经济利益出发, 利用区域地缘优势, 打破行政区划, 推进区域旅游的合作。 由此可见区域旅游合作是区域旅游经济发展的客观必然, 
是旅游业发展到一定阶段的需要, 也是地方旅游业发展成 熟的标志。实践充分证明, 旅游合作是消除区域利益冲突、 实现旅游业可持续发展重要举措[1]。

从区域经济学的角度看, 各子区域作为单独的经济体, 都有追求自身利益最大化的冲动。于是在旅游资源空间分 布差异性的条件下, 各地旅游部门均按自身的最优策略行 事, 以达到个体最佳, 但如果各方不合作, 个体最佳绝不 可能实现整体最佳。为了保证整体收益最大, 各区域必须 联合。在旅游业的发展中, 不同的地区在进行激烈竞争、 争夺客源的同时, 为了共同抵御风险, 提升区域竞争力, 主观上又需要联合起来, 形成紧密合作的竞合关系。区域 旅游合作是不同的区域为了实现自身的某些目标, 集结成 群并进行有效的资源整合, 以形成具有战略互补功能的整 体, 以弥补各自的不足, 突破发展的瓶颈, 最终实现共赢。

\section{3. 区域旅游合作主体分析}

区域旅游合作是区域旅游经济协作系统中各构成要素 之间的相互促进、相互制约的关系, 合作的过程实际上是 政府、旅游企业两个旅游开发主体之间进行反复博亦的过 程, 政府之间的合作机制实质上就是区域之间地方利益的 博竕过程。这种“博亦均衡”的结果将促成区域旅游合作制 度框架的建立。

\section{1 地方政府}

地方政府是行政区域决策主体、管理主体和利益主体, 对旅游业区域合作快速健康发展具有重要的推动作用。首 先, 政府是地方整体利益的代表和相对独立的行为主体, 政府层面的合作是实现区域共同利益最大化的基础和保 障; 其次, 政府又是区域经济中最有效的调控主体, 政府 的决策和调控不仅对本地旅游经济的发展具有重大影响, 而且也直接关系到跨行政区划、跨行政层级的利益协调; 同时, 政府还是规范旅游市场和竞争秩序的主体, 区域性 制度障碍的清除, 区域性旅游竞争行为的监管, 区域性旅 游发展环境的改善等, 均有赖于各地政府的合作与联动。 我国区域旅游合作实践表明, 各级政府是推动这一进程的 最重要力量。无论是旅游资源开发、旅游交通建设、旅游 市场促销方面的合作, 还是旅游信息服务、旅游人才培育 方面的许多合作，就是通过政府间的安排来进行的。因而 在区域旅游合作中加强地方政府之间的合作, 充分发挥政 府的调控作用, 有利于综合协调社会各方面的力量和资源, 推动区域旅游业的健康持续发展。

\section{2 旅游企业}

旅游企业是旅游经济的运行主体, 是旅游产品和服务 的生产者与提供者, 也是区域旅游合作中不可或缺的重要 力量。作为区域旅游合作的重要微观经济主体, 地区间旅 游企业的合作是旅游业区域合作的基础, 或者说区域旅游 合作是区域内旅游企业通过市场交换和市场竞争来实现 的。在市场经济条件下, 一方面, 大量旅游企业为适应竞 争和追求效益, 会不断优化配置自身的资源要素, 在细化 分工的基础上向专门化、专业化的方向演进。另一方面, 一些已具规模的旅游企业, 也会逐步在一定领域内形成系 列化、集团化的扩张。这两种情况都要求旅游企业突破行 政区划的界限而加强相互间的合作，从而在更大的空间范 围内形成有机的旅游产业链。

\section{3 非政府组织}

非政府组织同样是影响区域旅游发展与合作的一种重 要力量, 它既不同于政府, 也不同于企业, 而是连接两者 的桥梁与纽带, 是沟通协调各方关系、并提供相关服务的 中介组织。在区域旅游合作中, 非政府旅游组织在影响地 方法规和政府决策方面, 在加强行业自律和协调利益关系 方面, 在维护行业利益和竞争秩序方面, 在促进信息交流 和信息共享方面, 在开展专业培训和咨询服务方面, 在塑 造旅游形象和旅游品牌方面等, 都具有独特的、不容忽视 的作用。

这三个层面上的合作主体, 在区域旅游发展的不同时 点上, 地位和作用不尽相同。一般而言, 当潜在的区域旅 游合作的收益无法在现有的制度安排内实现时, 政府层面 的合作是最为关键的; 反之, 则企业层面的合作往往具有 更为重要的意义。当既定的制度条件下, 合作利益难以实 现或其帕累托改进难以有效时, 政府及其合作往往具有主 导性的作用; 反之, 则企业及其合作应成为推动区域旅游 合作的基本力量。

在区域旅游合作中, 政府、旅游企业和非政府旅游组 织是有机的组合, 缺一不可。在区域旅游合作中, 政府、 企业和非政府组织是三个不同层面上的合作主体。政府是 规划、调控和规范层面上的合作主体, 它们通过协调、服 务、监督、管理等职能, 为区域旅游经济的发展营造良好 的竞争秩序和发展环境; 企业是旅游经济运行层面上的合 作主体，它们通过资金、技术、人才、品牌等资源要素的 区域性组合, 实现自身利益的最大化; 而非政府组织则往 往是在政府失灵和市场失灵层面上的合作主体, 它们致力 于用非强制力的和非赢利性的方式, 来破解区域旅游发展 中一些市场和政府都无力顾及、或难以解决的问题[2]。 


\section{4. 区域旅游合作领域及内容}

要在坚持区域的协调发展和可持续发展原则指导下， 全面推进区域旅游合作，共同研究制定区域旅游发展规划 和市场开发政策。建立旅游资源和旅游产品开发建设招商 引资机制, 搭建旅游资源和产品开发的融资平台, 充分发 挥地区的资源优势和特色, 形成合作互动优势互补、互利 共赢、共同发展的格局[3]。

\section{1 塑造旅游整体形象}

从合作各方的旅游资源特色出发, 加大旅游资源的整 合力度, 统一规划区域内旅游资源, 使其形成一个旅游整 体对外推出。将旅游精品连接起来, 联合进行开发, 形成 整体形象, 对外统一宣传, 共同打造旅游品牌。

\section{2 共同开发精品旅游线路}

整合资源共同策划和推广精品旅游线路, 对旅游线路 进行优化组合, 以延伸旅游路线, 吸引周边旅游客源。充 分体现两地的联动发展, 按照旅游产业链来布局旅游经济, 合作开发旅游精品及各项专题产品。将境内景区有机结合, 串点成线, 串珠成链, 形成门类齐全、内容丰富、特色鲜 明、品质上乘的一大批适应国际国内多层次需求的旅游产 品系列, 实现资源共享、优势互补、互惠互利, 形成整体 优势。

\section{3 共同开拓旅游客源市场}

共同开拓客源市场, 是区域旅游合作的重要内容。一 是加强地区之间互相推介, 扩大合作规模, 扩大区域内 “互 为旅游客源地、互为旅游目的地” 的推广活动, 进一步扩大 合作范围; 相互宣传、互通资讯, 进行区域内客源的循环 流动, 实现区域内旅游客源的共享。二是联合营销, 共树 区域统一旅游品牌。共同开展市场调研、制定促销宣传计 划和方案, 联合参加国际国内重要旅游展览会, 拓展国内 外旅游市场, 打造区域旅游品牌和形象。三是共同策划系 列节庆活动, 以文化节庆为契机, 开展文化旅游交流活动。

\section{4 建立区域性旅游集团}

建立跨区域旅游集团可以保证旅游产品价值链的完整 性, 能够通过企业合作内部化, 避开某些行政壁垒, 有效 地实现跨区域要素组合, 提高资源配置效率; 能够打破各 旅游企业之间各自为战的局面, 避免区域内骨干经营单位 为争夺客源进行的恶性竞争, 有利于区域旅游一体化的实 施, 有利于将竞争提升到质量和品牌竞争的高度。跨行业 发展是区域经济一体化发展的重要特征, 旅游产业内不同
行业之间的旅游企业进行合作是实现区域旅游一体化的重 要途径。多元化发展旅游企业集团, 可以使更多的旅游合 作在集团内部进行，更有利于节约运作成本，促进区域旅 游合作的发展。

加快培育合作主体, 推动区域旅游企业联合。一是进 一步加大财政对旅游业发展的投入力度, 加速本地区大型、 品牌旅游企业集团的发展壮大, 鼓励有实力的民营企业进 入旅游业，尤其是对中小型旅游企业在税收方面给予一定 优惠政策, 培育有竞争力的市场主体; 二是通过资本重组 等一系列手段, 大力推动两地旅游企业跨区域重组和联合, 充分发挥各地区旅游企业优势, 针对重大项目加强资本合 作，给予政策优惠促进区域内有实力的企业共同开发，利 用资金纽带把区域利益主体联系在一起，实现利益共享。

\section{5 打造区域旅游产业集群}

旅游产业作为关联性极高的产业, 在某一特定的区域 内, 存在着以旅游目的地为核心为旅游者提供上中下游各 项配套服务的各种企业, 它们围绕旅游吸引物自然而然地 形成地理空间聚集。区域旅游合作成功的关键是旅游企业 之间的顺利合作, 而旅游产业集群能够促进旅游企业合作 的完成, 同时对形成统一的旅游形象、树立区域旅游品牌 具有不可忽视的重要作用。旅游产业集群必须依托一个主 导产业, 它可以是吃、住、行、游、娱、购等旅游产业链 上任何一个企业, 当这个主导产业做大做强时, 就能形成 品牌, 也必然会带动相关产业的发展, 由此形成旅游产业 集群品牌，带动整个区域旅游业的发展[4]。

\section{6 打造区域旅游产业链}

旅游企业按照价值链形成产业集群，可以自动实现旅 游产业结构的调整，有利于进行深层次的区域旅游合作。 大力发展相关配套产业, 促进区域旅游产业链向两端延伸, 形成合理的区域旅游产业结构。一是提升旅游要素功能, 联合改善区域旅游交通、餐饮、购物、住宿、娱乐等方面 的环境, 缩小地区间差距, 提升区域整体旅游要素功能, 增强旅游吸引力。二是促进旅游业与相关产业融合发展, 大力推动旅游业与金融业、文化创意产业以及会展业等相 关产业融合发展，占据旅游价值链的最高端，使旅游产业 从资源拉动型提升为产业联动型, 从而带动区域经济的整 体发展。

\section{5. 区域旅游合作的保障机制}

5.1 统筹协调与规划, 全面消除体制障碍

一是建立跨区域的、权威的协调机构。在内蒙古自治 
区旅游局、地方人民政府等有关部门的领导和支持下，设 立协调管理机构, 进行旅游合作的研究和管理工作, 其主 要职能包括: 旅游政策制定、旅游宣传促销、旅游线路开 发、相关的企业协调、有关产业部门和各级地方政府的关 系协调等。

二是制定跨区域旅游发展规划。打破行政区划, 统筹 考虑两地的区位条件、旅游资源禀赋、旅游发展基础和产 业特点, 在更大范围、更高层次上谋篇布局, 形成协作配 套、共同发展的格局, 全面提升区域旅游竞争力。制定和 完善赤峰与锡盟旅游发展战略性规划体系, 从全局发展出 发对产品开发进行合理布局, 科学安排开发时序, 以免出 现旅游资源重复开发、项目雷同等现象。两地应做好规划 的相互衔接, 注重开发独具特色的专题旅游产品, 在资源 共享的基础上实现优势互补, 防止因为距离较近产生同质 旅游产品的替代效应。

\section{2 完善利益共享和补偿机制, 实现区域整体利益最大化}

旅游合作的出发点是通过合作突破各地旅游发展的局 限, 形成合理的区域旅游产业体系, 其最终目的是实现区 域整体利益最大化。但在旅游合作运作过程中, 最困难的 问题是如何协调各方利益问题, 利益冲突也是旅游合作难 以深入进行的主要原因之一。因此, 如何协调各方面利益 就成为旅游合作的核心问题 [5]。

市场机制是推动区域旅游经济合作的最佳选择, 充分 发挥市场的主导作用, 让旅游要素在市场机制作用下自由 流动, 形成公平的竞争环境和平等的发展机会, 才能合理 分享经济利益。健全和完善旅游合作的利益共享和补偿机 制, 合作中获利较大的一方应该对在合作中利益受损的一 方, 在经济或者政策上予以相应的补偿, 从而实现旅游利 益在地区间的合理分配。

\section{3 消除市场壁垒, 促进旅游要素自由流动}

区域合作最重要的是实现旅游要素自由流动。双方应 清理和废止封锁市场的地方性保护政策, 努力消除限制和 影响要素顺畅流动的壁垒和障碍, 尽快建立起统一开放、 竞争有序、高效规范的市场体系, 促进合作双方生产要素 在区域内更加顺畅流动。应通过招商项目推介会、经贸洽 谈会、合作论坛、联谊会等多种形式, 为企业提供展示、 交易、交流、合作的平台, 推动合作区域内企业开展务实 合作，拓展市场、发掘商机、共同发展。

\section{4 加强旅游设施建设, 完善交通体系}

加强区域的协调和配合, 统一规划区域内的重大旅游
基础设施，通过共同投资联合建设，构建开放式、网络化 的基础设施体系。在内部交通方面, 加强主要景区连接交 通干线的旅游公路建设, 加快景区道路、通信、金融、环 保等设施建设, 并抓好配套设施建设, 建立完善重点旅游 景区和线路的医疗救护、治安报警、信息化等服务体系, 切实增强游客的安全感。

\section{5 构建区域旅游信息系统, 提供旅游公共信息}

各地旅游发展的实践证明, 旅游地受关注程度与信息 传播状况直接相关，信息披露越充分、传播渠道越广、传 播机制越完善, 形成的市场影响力和吸引力越大。通过区 域旅游合作, 实现旅游信息资源共享, 消除旅游信息不对 称和不确定性带来的信息失灵, 放大旅游信息的传播效应。 一是要构建区域性的专业化旅游信息平台, 提供覆盖面广、 全天候的旅游信息服务。二是建立有影响力的旅游电子商 务平台, 通过在线交易、网上支付等功能, 促进旅游服务 的便利化。三是加大信息技术在旅游业中的应用，提升旅 游景区的信息化服务水平，为游客提供更加便捷的信息服 务[6]。

\section{6 加强旅游行业管理, 提升旅游服务水平}

一是发挥旅游行政管理部门、行业协会和骨干企业的 作用, 研究制定针对区域旅行社、旅游饭店、旅游景区的 管理规范, 共同推动旅游服务标准化, 全面提高旅游服务 质量。二是整合区域旅游教育资源, 加强旅游教育和培训, 扩大旅游教育合作与交流, 提高旅游人才整体素质。三是 加大旅游市场监管力度, 加强区域旅游诚信体系建设, 完 善游客投诉处理、矛盾化解和突发事件应急处置机制。

\section{参考文献(References)}

[1] Gao Ming. Based on Game Theory Concurrence of Regional Tourism, Gui hai FORUM, 2008.3, pp.57-60.

[2] Ge Licheng, etc. China Regional Tourism Cooperation, Business Economics and Management, 2007.1, pp.70-75.

[3] Zhang zhichen. On regional tourism cooperation in the process of coordinating mechanism innovation, Theory and modern, 2011.5, pp.45-50.

[4] Jin Yuanyuan. Tianjin Regional Tourism Cooperation and Countermeasures Research, Commercial Research, 2009.4, pp.152-155.

[5] Qin Suping. Guangxi Xijiang River Economic Belt Regional Tourism Cooperation, Guilin Institute of Aerospace Engineering, 2012.4, pp.370-376.

[6] Xue Hao Guangdong West Regional Tourism Cooperation and Institutional Innovation, Journal of Southern, 2011.3, pp.29-32. 